\title{
Cutaneous Vasculitis with Renal Impairment in Octogenarian
}

\author{
Thiago Sande Miguel1, Bruna Sande Miguel2, Vinicius Sande Miguel'2, Jair Baptista Miguel'3, \\ Sebastião Celio Horta Coelho Filho ${ }^{1}$, Nayrton Kalys Cruz dos Anjos ${ }^{1}$, Lívia Cristina de Melo Pino', \\ Paola Stephanie Azevedo de Sá1, Vitor Araújo Goulart'1, Daniel Almeida da Costa1
}

\author{
${ }^{1}$ The Medical School at the Center of Higher Education of Valença, Valença, Brazil \\ ${ }^{2}$ Unigranrio Medical School, Rio de Janeiro, Brazil \\ ${ }^{3}$ The Medical School at the Center of Higher Education of Valenca, Valenca, Brazil \\ Email: professordanielfmv@gmail.com
}

How to cite this paper: Miguel, T.S., Miguel, B.S., Miguel, V.S., Miguel, J.B., Filho, S.C.H.C., dos Anjos, N.K.C., Pino, L.C.M., de Sá, P.S.A., Goulart, V.A. and da Costa, D.A. (2017) Cutaneous Vasculitis with Renal Impairment in Octogenarian. Journal of Biosciences and Medicines, 5, 37-45.

https://doi.org/10.4236/jbm.2017.56004

Received: May 10, 2017

Accepted: June 24, 2017

Published: June 27, 2017

Copyright $\odot 2017$ by authors and Scientific Research Publishing Inc. This work is licensed under the Creative Commons Attribution International License (CC BY 4.0).

http://creativecommons.org/licenses/by/4.0/

\begin{abstract}
Henoch-Schönlein purpura is a vasculitis of small vessels, characterized by tissue deposition of IgA, affecting predominantly the skin, intestine, joints and kidneys. It mainly affects the pediatric age group, especially from 2 to 11 years old. Most often, it is preceded by episode of upper airway infection from days to weeks. The most common clinical manifestations are purpuric cutaneous lesions located in the lower limbs and buttocks, abdominal pain in colic, nausea, vomiting, diarrhea, in addition to arthralgia/arthritis, usually with spontaneous resolution. Renal impairment usually manifests with hematuria and proteinuria, and renal function may also be impaired. The case described refers to a female patient, 86 years old, with a previous history of infection of the upper airways, followed by purpura in the lower limbs and renal impairment: serum creatinine $3.1 \mathrm{mg} / \mathrm{dL}(\mathrm{N} 0.5-1.2 \mathrm{mg} / \mathrm{dL}$ ); glomerular filtration rate $15 \mathrm{ml} / \mathrm{min}(\mathrm{N}>60 \mathrm{ml} / \mathrm{min})$; urea $118 \mathrm{mg} / \mathrm{dL}(\mathrm{N}<40 \mathrm{~g} / \mathrm{dL})$; proteinuria $4.497 \mathrm{mg} / 24 \mathrm{~h}$. The present report aims to draw attention to the occurrence of Henoch-Schönlein purpura in an atypical age group, with significant renal impairment, improvement only with conservative treatment, thus avoiding the use of immunosuppressants and the risks of immunosuppression and toxicity related to such drugs.
\end{abstract}

\section{Keywords}

Purple Henoch-Schönlein, Vasculitis, Renal, Elderly, Case Report

\section{Introduction}

Henoch-Schönlein purpura (PHS), also known as anaphylactoid purpura, allergic purpura, or non-thrombocytopenic rheumatic purpura, is the most prevalent 
vasculitis in the pediatric age group [1] [2]. It is characterized by the involvement of small vessels, venules and arterioles [3] [4].

First described in 1801 by William Heberden [5] [6], it was originally referred to as Willan-Heberden's disease. In 1837 Johann Lukas Schönlein recognized the association between purpura and arthritis [5] [7]. Eduard Heinrich Henoch later reported a case that also included abdominal pain, bloody diarrhea, and renal involvement [5].

Such pathology is characterized by skin lesions in $100 \%$ of cases [3], with symmetrical localization mainly in the buttocks and lower limbs [2], gastrointestinal symptoms of $35 \%$ to $85 \%$, renal alterations of $44 \%$ to $47 \%$ and arthralgia in $60 \%$ to $84 \%$ [4].

The overall incidence in children was estimated at 13.5 cases per 100,000 children. However, the true incidence is probably underestimated because cases are not often reported to public health agencies [6] [8].

Although the cause is unknown, it usually follows upper respiratory tract infection in days or weeks in up to $50 \%$ of cases [5] [9] [10] [11]. It has been proposed that beta-hemolytic group A streptococcus can be involved as a triggering factor, as well as the use of medications and vaccines and contact with specific food allergens, such as dyes and preservatives [9].

There is a seasonal predominance in spring and winter between children and in the summer among adults. It is especially common among children, being the most affected male sex [12]. The peak incidence occurs between the ages of 2 and 11 years old. It is more common among Hispanics and whites. PHS is the most common form of vasculitis in childhood, but there are cases described up to 89 years of age, although $50 \%$ of all cases occur before 5 years of age, presenting more severe renal manifestations in adulthood, especially with the elderly, which may impact their life expectancy [10] [13] [14].

It is generally presented as a classic tetrarch of rash, abdominal pain, renal disease and polyarthralgia [6] [10] [14]. Cutaneous lesions represent extravasation of blood in the skin, and often occur in groups that may persist for 3 to 10 days [14] [15]. The abdominal pain is the colic type, frequently manifested within 8 days after the onset of rash, associated with episodes of nausea, vomiting and diarrhea, or constipation and the presence of blood and faeces [15]. Renal impairment is the major prognostic factor of PHS [16]. The most evident changes are transient hematuria and proteinuria, with shorter durations for 1 month [4]. The prognosis is usually favorable, but some patients with nephritis may progress to renal failure [2], characterized by systemic arterial hypertension, impaired renal function and glomerulonephritis [17]. polyarthralgia usually affects associated knees and ankles with spontaneous resolution [18] [19]. Cutaneous, gastrointestinal, renal and articular involvement are common features of the pathology, whereas orchitis, pulmonary haemorrhage and vasculitis of the central nervous system (CNS) are rarely evidenced [2].

The diagnosis and the better knowledge of the etiopathogeny of vasculitis have made considerable progress in recent years, but there are still many points to be 
clarified in this group of diseases, given their heterogeneity and difficult therapeutic decisions [4] [17].

PHS is a systemic vasculitis characterized by the deposition of immunoglobulin A (IgA). In the histopathological examination, there is a cutaneous component with lesions consisting of subepidermal hemorrhages and necrotizing vasculitis of the small vessels of the dermis [19]. The deposition of IgA, a prominent feature of fluorescence microscopy [3] [20], is present in these vessels.

Cutaneous biopsies in which the subcutaneous tissue is not represented are inadequate for the investigation of vasculitis affecting small vessels. The pathophysiology of cutaneous vasculitis may be due to five major mechanisms: hypersensitivity mechanisms; mediated by type 1 reaction of Gel and Coombs, with active participation of eosinophils; Type 2 reaction of Gel and Coombs (antibody-mediated cytotoxicity); Immunocomplex mediated disease; and direct affection of the vessel [19].

The presence of palpable purpura with the other components of tetrad makes the diagnosis straightforward. However, it is necessary to rule out other systemic auto-immune diseases, such as other forms of vasculitis or juvenile rheumatoid arthritis. Few laboratory tests are useful for diagnosis. Often mild leukocytosis with a normal platelet count is found. Elevation of IgA in the blood occurs in half of the patients and the definitive diagnosis is confirmed by a sample biopsy of the skin or kidney that has IgA deposition [10] [12]. In 1990, the American College of Rheumatology developed criteria for the diagnosis of PHS (Table 1). The diagnosis is given when the patient presents at least 2 of the 4 criteria.

The acute and active phase of PHS has spontaneous resolution in $94 \%$ of children and $89 \%$ of adults [13]. The patient should be checked for rare but serious complications such as hemorrhagic involvement of the renal, pulmonary, gastrointestinal, genitourinary and system central nervous system or joints, which usually occur within four weeks of the initial presentation, but may occur up to the eighth week. Serious kidney complications require referral to a nephrologist.

Regarding treatment, joint pain and painful soft tissue edema usually respond to acetaminophen or non-steroidal anti-inflammatory drugs [18], but oral prednisone, from 1 to $2 \mathrm{mg} / \mathrm{kg}$ per day, may be necessary to accelerate its resolution [19]. Anti-inflammatory agents should be avoided in patients with extensive renal involvement.

Specific treatment of renal leukemia should be considered only in patients with significant proteinuria and with decreased glomerular filtration rate during

Table 1. Criteria for classification of Henoch-Schölein purpura.

\begin{tabular}{cl}
\hline Purple palpable & Elevated purpura, not related to thrombocytopenia \\
Age of onset less than 20 years & Age of onset of symptoms less than 20 years \\
Abdominal angina & $\begin{array}{l}\text { Diffuse abdominal pain that intensifies with meals or } \\
\text { intestinal bleeding }\end{array}$ \\
Changes in cutaneous biopsy & Histology showing granulocytes in arterioles or venules \\
\hline
\end{tabular}


the acute episode. In these situations, a renal biopsy should be performed to assess the severity of the histological lesions, particularly the degree of growth, which seems to be the best prognostic indicator [13] [19]. The therapy is based on corticosteroids in high doses, alone or combined with immunosuppressive agents such as azathioprine, cyclophosphamide, or cyclosporine, in addition to warfarin and dipyridamole; high dose of immunoglobulins; plasmapheresis and renal transplantation [5] [7] [19].

The aim of this report was to aggregate knowledge and stimulate the discussion of differential diagnoses of vasculitis in the elderly with their systemic manifestations, including the rarest forms of vascular involvement in this age group. Thus, generating a broader view of these pathologies, so that they are treated in a timely and appropriate manner, avoiding possible sequels.

\section{Case Report}

An 86 years old patient, female, white, seamstress, widow, native of Santo Antônio de Pádua-RJ, Brazil. She presented with comorbidities, hypertension for 36 years in irregular treatment with losartan $100 \mathrm{mg} /$ day, amlodipine $5 \mathrm{mg} /$ day, spironolactone $25 \mathrm{mg} /$ day and furosemide $40 \mathrm{mg} /$ day, and diabetes mellitus, 30 years ago using metformin $1500 \mathrm{mg} /$ day and glibenclamide $10 \mathrm{mg} /$ day and peripheral arterial disease for 10 years using cilostazol $100 \mathrm{mg} /$ day. She denied other comorbidities, food or drug allergies, smoking or alcoholism and previous surgeries.

She sought emergency room in August 2012, due to a history of upper airway infection (IVAS), myalgia, holocranial headache, vomiting, abdominal pain, and diabetes for approximately one week. On admission, she was in a regular state of being hypoxic $(+/ 4)$, acyanotic, anicteric, axillary temperature $37.2^{\circ} \mathrm{C}$, dehydrated (++/4), PA: 160/90mmHg, HR: 108 bpm, RF: 18 ipm, cardiac and pulmonary auscultation without alterations. During hospitalization, there was improvement of the above picture. In parallel to the picture, there were purulent, maculopapular, erythematous lesions in the lower limbs and buttocks, not pruritic or desquamative. The laboratory tests performed at the time are shown in Table 2

After resolving the condition, she was discharged from the hospital with a referral to the nephrology department, due to the retention of nitrogenous slags and proteinuria, where was asked for kidney and urinary tract ultrasound, biopsy of skin and renal lesions, and the latter was not performed due to patient refusal. Ultrasonography demonstrated topical kidneys of normal size, preserved echogenicity, cortico-medullary relationship compatible with the age of the patient. Skin biopsy demonstrated small vessels containing fibrin, neutrophils, and sometimes necrosis of the wall. Around it, there was extravasation of red blood cells and some neutrophils. Vessels of the deep plexus and of medium caliber free of lesions.

After discussing with the patient and family members about the therapeutic possibilities involving the use of corticosteroids, immunosuppressants and 
Table 2. Results of laboratory tests.

\begin{tabular}{ccc}
\hline Laboratory tests & Results & Normal \\
\hline Leukometry & $12,480 / \mathrm{mm}^{3}$ & $5000-10,000 / \mathrm{mm}^{3}$ \\
C reactive protein & $12 \mathrm{mg} / \mathrm{L}$ & $<6 \mathrm{mg} / \mathrm{L}$ \\
Lactic dehydrogenase & $320 \mathrm{UI} / \mathrm{L}$ & $135-214 \mathrm{UI} / \mathrm{L}$ \\
Erythrocyte sedimentation rate & $60 \mathrm{~mm} / 1 \mathrm{~h}$ & $\leq 10 \mathrm{~mm} / \mathrm{hh}$ \\
Platelet count & $250,000 / \mathrm{mm}^{3}$ & $150,000-450,00 / \mathrm{mm}^{3}$ \\
Prothrombin activity & $92 \%$ & $70 \%-100 \%$ \\
INR & 1 & $1-1.5$ \\
Alkaline phosphatase & $40 \mathrm{UI} / \mathrm{L}$ & $25-100 \mathrm{UI} / \mathrm{L}$ \\
TGO & $26 \mathrm{UI} / \mathrm{L}$ & $\leq 31 \mathrm{UI} / \mathrm{L}$ \\
TGP & $28 \mathrm{UI} / \mathrm{L}$ & $\leq 31 \mathrm{UI} / \mathrm{L}$ \\
GGT & $33 \mathrm{UI} / \mathrm{L}$ & $\leq 43 \mathrm{UI} / \mathrm{L}$ \\
Serum creatinine & $3.1 \mathrm{mg} / \mathrm{dL}$ & $0.5-1.2 \mathrm{mg} / \mathrm{dL}$ \\
Glomerular filtration rate & $15 \mathrm{ml} / \mathrm{min}$ & $>60 \mathrm{ml} / \mathrm{min}$ \\
Urea & $118 \mathrm{mg} / \mathrm{dL}$ & $<40 \mathrm{mg} / \mathrm{dL}$ \\
Proteinuria & $4497 \mathrm{mg} / 24 \mathrm{hours}$ & $<150 \mathrm{mg} / 24 \mathrm{hours}$ \\
\hline & & \\
\hline & &
\end{tabular}

measures of blood pressure control and proteinuria, we chose only to institute the treatment of the last two through the use of losartan $50 \mathrm{mg}, 12 / 12 \mathrm{~h}$. After four months of treatment initiation, proteinuria was $690 \mathrm{mg} / 24 \mathrm{~h}$ and serum creatinine $1.18 \mathrm{mg} / \mathrm{dL}$. On November 2014, still using losartan in the dose described above, the patient presented Proteinuria $783 \mathrm{mg} / 24 \mathrm{~h}$ and serum creatinine of $1.37 \mathrm{mg} / \mathrm{dL}$.

Although, in spite of all the patient-directed clinical follow-up and support, the patient opted only for blood pressure control and undertook the most detailed clinical follow-up of the condition from November 2014.

The patient was previously and properly explained about the report of her pathological condition, being in agreement with the publication of the same and signing the Term of Free and Informed Consent.

Figure 1 shows the detail of the infiltrate of neutrophils around the vessel with extravasated red blood cells (HE, 400x original increase).

\section{Discussion}

According to Roberts et al. [14], PHS is more prevalent in childhood, in the age group between 02 and 11 years old, with half of the cases occurring before the age of 5 years. The frequency of this purpura is lower in adults, corresponding to $20 \%-30 \%$ of the cases [21], which there is less knowledge about this condition in this age group, and especially in the elderly. Therefore, we deem it relevant to report this case. In addition, it must be emphasized that adult age involvement has a worse prognosis.

According to Brandt et al. [22], the purpura can be preceded, for a period va- 


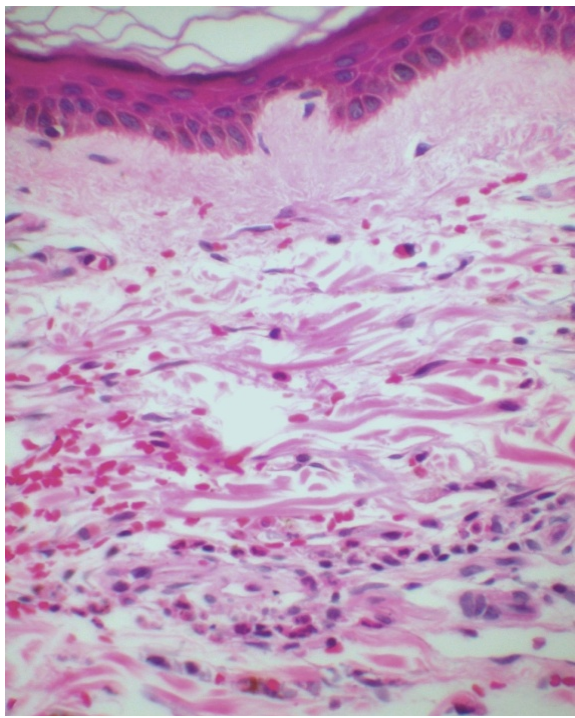

(a)

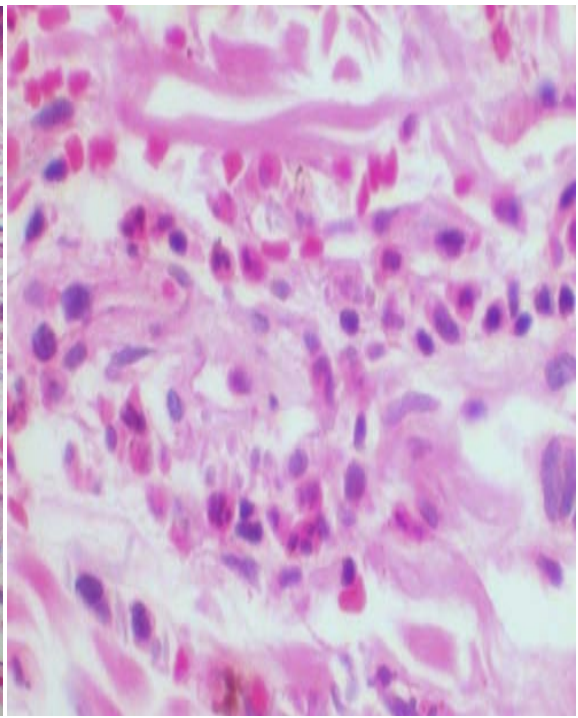

(b)

Figure 1. Detail of the infiltrate of neutrophils * around the vessel with extravasated red blood cells ${ }^{*}$ (HE, 400x original increase).

rying from one to three weeks, by IVAS or streptococcal infection, the latter being involved in about one third of the cases, as well as the use of drugs and vaccines and contact with allergens. In the case presented, the patient started with IVAS, myalgia, headache, vomiting, abdominal pain and adynamia one week before the appearance of purpuric skin lesions. The presence of dyspnea, abdominal pain and vomiting may be the initial symptoms of PHS in $40 \%$ of the cases, a compatible picture presented by the patient in the emergency room [23].

Brandt et al. [22], further states that rashes may precede typical cutaneous manifestations, characterized by symmetrical hemorrhagic petechiae or palpable purpura in the limbs and gluteal region, sparing the trunk in general. The lesions reported in the present case presented as maculopapular, erythematous, nonpruritic or scaly lesions, purpuric and located below the waist line.

The diagnosis of PHS according to the American College of Rheumatology necessitates the presence of 2 of 4 previously mentioned criteria [6]. In this case, the following criteria may be cited: alteration in the biopsy of skin consisting of small vessels containing fibrin, neutrophils and sometimes, necrosis of the wall. In the perivascular region, there is extravasation of red blood cells and some neutrophils, and palpable purpura of $250,000 / \mathrm{mm}^{3}\left(\mathrm{~N} 150,000-450,000 / \mathrm{mm}^{3}\right)$.

Renal impairment is apparently more prevalent in older children and adults, usually manifesting as hematuria with or without hematic cylinders, and in mild or even absent proteinuria [21]. Nephrotic syndrome, elevated creatinine and hypertension are present in the minority of patients. These findings are associated with increased risk of progressive renal disease and occur more frequently in adults [21]. The laboratory tests during the hospitalization are shown in Table 3.

Although the patient did not present a fever and the cutaneous lesions were restricted to the buttocks and lower limbs, it evolved with impaired renal func- 
Table 3. Laboratory tests during hospitalization.

\begin{tabular}{ccc}
\hline Laboratory tests & Results & Normal \\
\hline Serum creatinine & $3.1 \mathrm{mg} / \mathrm{dL}$ & $0.5-1.2 \mathrm{mg} / \mathrm{dL}$ \\
Glomerular filtration rate & $15 \mathrm{ml} / \mathrm{min}$ & $>60 \mathrm{ml} / \mathrm{min}$ \\
Urea & $118 \mathrm{mg} / \mathrm{dL}$ & $<40 \mathrm{mg} / \mathrm{dL}$ \\
Proteinuria & $4497 \mathrm{mg} / 24 \mathrm{~h}$ & $<150 \mathrm{mg} / 24 \mathrm{~h}$ \\
VHS & $60 \mathrm{~mm} / 1 \mathrm{~h}$ & $\leq 10 \mathrm{~mm} / \mathrm{hh}$ \\
\hline
\end{tabular}

tion, with increased nitrogen slags, proteinuria and decreased renal function, evidenced by a decrease in glomerular filtration rate, requiring referral to the nephrology department.

The diagnosis of renal impairment is based on clinical presentation, with renal biopsy being reserved for cases of uncertain diagnosis or more severe renal impairment (proteinuria $>1 \mathrm{~g} / 24 \mathrm{~h}$ or a decrease in renal function) [24]. From renal biopsy findings a percentage of growing glomeruli appears to be the most important prognostic indicator [24]. Corticosteroid and immunosuppressive therapy should be considered only in patients with significant proteinuria or decreased renal function [24]. For cases of milder renal involvement with only microscopic or gross macroscopic hematuria, discrete proteinuria should only be monitored for the observation of worsening of proteinuria or renal function and control of blood pressure [24]. Biopsy and the use of corticosteroids and immunosuppressants are avoided in these cases. However, the patient refused the renal biopsy and opted only for the control of the arterial pressure and of proteinuria with an angiotensin II receptor blocking drug. In view of this, although it was explained about the importance of adequate treatment and its clinical-laboratorial follow-up, it was not possible to obtain further details of the long-term follow-up of the pathology, since the continuation of the case was impossible for the patient.

\section{Conclusion}

The low frequency and the scarce literature on PHS in the advanced age group emphasize the need to discuss the present case, the diagnosis of which should be remembered in elderly patients affected by cutaneous vasculitis with renal involvement. The good evolution of the case without the use of specific immunosuppressive drugs, after discussing, the patient and family, emphasizes the necessity of the shared decision making as an objective to avoid aggressive treatment, in a situation where the therapeutic index bordering could cause harm to the patient, besides its basic pathological picture.

\section{Acknowledgements}

Thanks to the Center of Higher Education of Valença of Dom André Arcoverde Foundation. 


\section{References}

[1] Bailey, M., et al. (1998) The Effects of Vasculitis on the Gastrointestinal Tract and Liver. Gastroenterology Clinics of North America, 27, 747-782. https://doi.org/10.1016/S0889-8553(05)70032-7

[2] Kiss, M.H.B., et al. (1994) Clinical, Laboratory and Therapeutic Aspects of 46 Children with Henoch-Schönlein Purpura. The Journal of Pediatrics, 70, 234-239. https://doi.org/10.2223/JPED.716

[3] Fervenza, F.C. (2003) Henoch-Schönlein Purpura Nephritis. International Journal of Dermatology, 42, 170-177. https://doi.org/10.1046/j.1365-4362.2003.01769.x

[4] Kaku, Y., Nokara, K. and Honda, S. (1998) Renal Involvement in HenochSchönleinpurpura: A Multivariate Analysis of Prognostic Factors. Kidney International, 53, 1755-1759. https://doi.org/10.1046/j.1523-1755.1998.00915.x

[5] Ballinger, S. (2003) Henoch-Schönlein Purple. Current Opinion in Rheumatology, 15, 591-594. https://doi.org/10.1097/00002281-200309000-00012

[6] Mills, J.A., Michel, B.A., Bloch, D.A., et al. (1990) The American College of Rheumatology 1990 Criteria for the Classification of Henoch-Schönlein Purpura. Arthritis \& Rheumatology, 33, 1114-1121. https://doi.org/10.1002/art.1780330809

[7] Blanco, R., Martinez-Taboada, V.M., Rodriguez-Valverde, V., et al. (1997) Henoch-Schönlein Purpura in Adulthood and Childhood: Two Different Expressions of the Same Syndrome. Arthritis \& Rheumatology, 40, 859-864. https://doi.org/10.1002/art.1780400513

[8] Saulsbury, F.T. (2001) Henoch-Schönlein Purple. Current Opinion in Rheumatolo$g y$, 13, 35-40. https://doi.org/10.1097/00002281-200101000-00006

[9] Ronkainen, J., et al. (2003) Outcome of Henoch-Schönlein Nephritis with Nephrotic-Range Proteinuria. Clinical Nephrology, 60, 80-84.

[10] Robson, W.L. and Leung, A.K. (1994) Henoch-Schönlein Purple. Advances in Pediatrics, 41, 163-194.

[11] Szer, I.S. (1994) Henoch-Schönlein Purple. Current Opinion in Rheumatology, 6, 25-31. https://doi.org/10.1097/00002281-199401000-00005

[12] Halling, S.F., Soderberg, M.P. and Berg, U.B. (2005) Henoch Schönleinnephritis: Clinical Findings Related to Renal Function and Morphology. Pediatric Nephrolo$g y, 20,46-51$. https://doi.org/10.1007/s00467-004-1650-6

[13] Gedalia, A. (2004) Henoch-Schönlein Purpura. Current Opinion in Rheumatology, 6, 195-202. https://doi.org/10.1007/s11926-004-0068-2

[14] Roberts, P.F., et al. (2007) Henoch-Schönlein Purpura: A Review Article. Southern Medical Journal, 100, 821-824. https://doi.org/10.1097/SMJ.0b013e3180f62d0f

[15] Leung, A.K. and Chan, K.W. (2001) Evaluating the Child with Purple. American Family Physician, 64, 419-429.

[16] Shin, J.I., et al. (2006) Predictive Factors for Nephritis, Relapse, and Significant Proteinuria in Childhood Henoch-Schönlein Purpura. Scandinavian Journal of Rheumatology, 35, 56-60. https://doi.org/10.1080/03009740510026841

[17] Stewart, M., et al. (1988) Longterm Renal Prognosis of Henoch-Schönlein Purpura in an Unselected Childhood Population. European Journal of Pediatrics, 147, 113115. https://doi.org/10.1007/BF00442205

[18] Giangiacomo, J. and Tsai, C.C. (2007) Dermaland Glomerular Deposition of IgA in Anaphylactoid Purpura. American Journal of Diseases of Children, 131, 981-983.

[19] Rostoker, G. (2001) Schönlein-Henoch Purpura in Children and Adults: Diagnosis, 
Pathophysiology and Management. BioDrugs, 15, 99-138.

https://doi.org/10.2165/00063030-200115020-00004

[20] Saulsbury, F.T. (2002) Epidemiology of Henoch-Schönlein Purpura. Cleveland Clinic Journal of Medicine, 69, SII87-9.

https://doi.org/10.3949/ccjm.69.suppl_2.sii87

[21] Dedeoglu, F. and Kim, S. (2017) Schönlein-Henoch Purpura (Immunoglobulin A Vasculitis): Clinical Manifestations and Diagnosis.

https://www.uptodate.com/contents/henoch-schonlein-purpura-immunoglobulin-v asculitis-clinical-manifestations-and-diagnosis

[22] Brandt, H.R.C., Arnone, M., Valente, N.Y.S., Criado, P.R. and Sotto, M.N. (2017) Vasculite cutânea de pequenos vasos: Etiologia, patogênese, classificação e critérios diagnósticos-Parte I. Anais Brasileiros de Dermatologia, 82, 387-406. https://doi.org/10.1590/S0365-05962007000500002

[23] Brandt, H.R.C., Arnone, M., Valente, N.Y.S., Criado, P.R. and Sotto, M.N. (2007) Vasculite cutânea de pequenos vasos: Subtipos e tratamento-Parte II. Anais Brasileiros de Dermatologia, 82, 499-511.

http://www.scielo.br/scielo.php?script=sci_arttext\&pid=S0365-05962007000600002 \&lng $=\mathrm{pt}$

[24] Niaudet, P., Appel, G.B. and Hunder, G.G. (2017) Renal Manifestationsof Henoch-Scholein Purpura (IgAvasculitis). Basow, D., Ed., UptoDate, Waltham, MA. https://www.uptodate.com/contents/renal-manifestations-of-henoch-schonlein-pur pura-iga-vasculitis

Submit or recommend next manuscript to SCIRP and we will provide best service for you:

Accepting pre-submission inquiries through Email, Facebook, LinkedIn, Twitter, etc. A wide selection of journals (inclusive of 9 subjects, more than 200 journals)

Providing 24-hour high-quality service

User-friendly online submission system

Fair and swift peer-review system

Efficient typesetting and proofreading procedure

Display of the result of downloads and visits, as well as the number of cited articles

Maximum dissemination of your research work

Submit your manuscript at: http://papersubmission.scirp.org/

Or contact jbm@scirp.org 